\title{
Processo evolutivo de contaminação da Baía de Chacororé
}

\author{
Geraldo L. Diniz Andre Krindges \\ Depto de Matemática, ICET, UFMT, \\ 78060-900, Cuiabá, MT. \\ E-mail: geraldo@ufmt.br, krindges@gmail.com,
}

\section{Milton O. Assunção Jr.*}

Instituto de Computação - UFMT.

78060-900, Cuiabá, MT.

E-mail: assuncao_milton@yahoo.com.br.

\section{RESUMO}

Neste trabalho foram considerados apenas os poluentes oriundos dos afluentes contaminados da baía, para mostrar a necessidade de investimentos do poder público em saneamento básico. No modelo, foram levados em consideração os fenômenos de difusão efetiva, transporte pelo meio aquático, os fenômenos de degradação e as fontes poluidoras para a representação o problema $[1,2]$. Na construção de soluções aproximadas para equações diferenciais parciais que modelam este tipo problema se usou o método de elementos finitos de segunda ordem, após a discretização do domínio com a introdução de uma malha sobre a qual está definida a solução aproximada, devido a sua maior estabilidade para o código numérico que foi gerado. Para a discretização temporal, foi utilizado o método de Crank-Nicolson, por se tratar de um método incondicionalmente estável. O código numérico foi implementado em ambiente MATLAB ${ }^{\circledR}$, devido a sua facilidade de interface gráfica e funcionalidade para sistemas de grande porte. Os resultados estão apresentados na forma de simulação de cenário, para uma das estações bem caracterizadas da região, no caso a estação seca, através de gráficos mostrando o processo evolutivo de contaminação na área de estudo.

Palavras-chave: Poluição ambiental, modelagem matemática, equação reação-advecção-difusão.

\section{Objetivos}

- Descrever a contaminação da baía de Chacororé, através de um modelo matemático.

- Desenvolver códigos numéricos apropriados para simulaçãao de cenários.

- Avaliar o modelo proposto e os códigos implementados com dados reais publicados na literatura.

\section{Descrição da área de estudo}

A área de estudo foi delimitada a partir de uma imagem obtida através do Google Earth, cuja fronteira do domínio foi dividida em dez componentes, de $\Gamma_{0}$ a $\Gamma_{9}$, das quais $\Gamma_{0}, \Gamma_{2}, \Gamma_{4}, \Gamma_{6}$ e $\Gamma_{8}$ representam as margens da Baía de Chacororé, enquanto $\Gamma_{1}$ e $\Gamma_{3}$ ao sudoeste representam os pontos de deságue de seus tributários e que são as fontes de descarga dos poluentes. Já as componentes $\Gamma_{5}$ ao sudoeste, $\Gamma_{7}$ e $\Gamma_{9}$ ao leste representam os pontos de sangradouro.

Essa região foi então discretizada para uma malha de elementos finitos triangulares, construída pelo software livre Gmsh - versão 2.4.2, sobre os quais foram efetuadas as aproximações, através de funções de segunda ordem.

Para obter a velocidade de transporte no meio aquático, essencial para a construção do código numérico que gerou as simulações dos cenários, foi utilizada a equação de Stockes, com código numérico apropriado ao problema, em ambiente MATLAB ${ }^{\circledR}$.

\footnotetext{
*bolsista de Iniciação Científica PIBIC/CNPq
} 


\section{Resultados}

De acordo com as condições da baía (figura 1(a)) se obteve o campo de velocidade de transporte no meio aquático, gerado pela equação de Stokes (figura 1(b)).

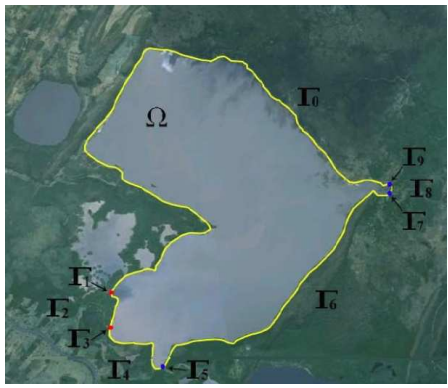

(a) Área de estudo

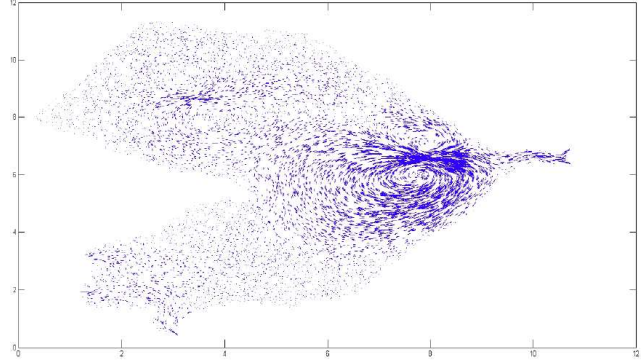

(b) Campo de transporte no meio.

Figura 1: Baía de Chacororé/MT e campo de velocidades

As figuras 2(a) e 2(b) referem-se a simulação obtida para a estação seca.

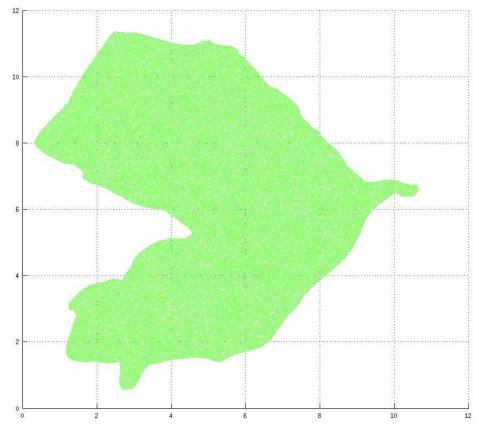

(a) Condição inicial $(t=0)$

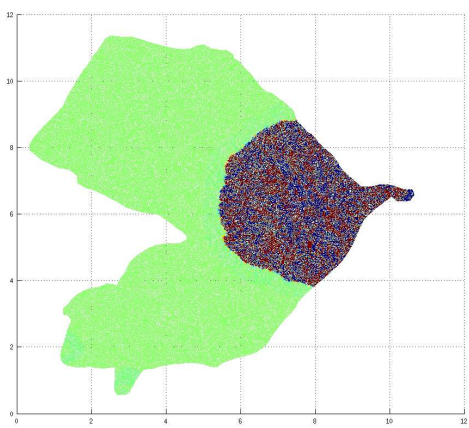

(b) Contaminação da baía em $t=50 \mathrm{~h}$.

Figura 2: Contaminação da Baía de Chacororé/MT - estação seca.

\section{Conclusões}

O campo de transporte descreve a maneira como os poluentes oriundos dos afluentes são carregados no meio aquático em função do fenômeno advectivo, cabe ressaltar o surgimento de alguns vórtices devido as condições de fronteira que não estavam previstos inicialmente. Por fim, o modelo e o código numérico mostraram-se eficientes para o sistema estudado, principalmente devido ao elevado número de nós (370593) e elementos (186222).

Os resultados obtidos podem contribuir para o prosseguimento dos estudos realizados a respeito dos impactos ambientais provocados por atividades antrópicas sobre a região do pantanal mato-grossense, bem como auxiliar no desenvolvimento de práticas de preservação ambiental, uma vez que alterando os valores de entrada do código é possível simular diferentes cenários de contaminação ou descontaminação.

\section{Referências}

[1] R. C. Bassanezi e W. C. Ferreira Jr.,"Equações Diferenciais com Aplicações”, Ed. Harbra, S. Paulo, 1988.

[2] P. E. Carreras e A. N. Menéndez, Mathematical simulation of pollutant dispersion, Ecological Modelling, 52 (1990) 29-40. 